\title{
Conceitos em Relações Internacionais
}

\author{
Concepts in International Relations
}

AMADO LUIZ CERVO*

Rev. Bras. Polít. Int. 51 (2): 8-25 [2008]

\section{Introdução}

O propósito desse texto é de analisar o nexo entre teorias de relações internacionais e conceitos aplicados às relaçôes internacionais ${ }^{1}$. Dois problemas são investigados a esse respeito: por um lado, o alcance explicativo de teorias e conceitos, por outro, seu enfoque nacional ou regional. Pretende-se confrontar o papel dos conceitos ao das teorias mediante hipótese segundo a qual conceitos e teorias exercem papéis diferenciados no campo de estudo das relações internacionais. $\mathrm{O}$ passo seguinte consiste em afirmar que o alcance explicativo universal das teorias é forjado, visto que se vinculam a interesses, valores e padrões de conduta de países ou conjuntos de países onde são elaboradas e para os quais são úteis, contrariamente aos conceitos, que expõem as raízes nacionais ou regionais sobre as quais se assentam e se recusam estar investidos de alcance explicativo global.

Essa linha de argumentação sugere reduzir a função das teorias e elevar o papel dos conceitos, seja no sentido de produzir compreensão, seja no sentido de subsidiar processos decisórios nas relações internacionais. Ademais, essa argumentação coloca em cheque o prestígio das teorias de relaçōes internacionais nos programas de ensino e advoga a pesquisa dos conceitos produzidos em determinado país ou num conjunto de países.

O texto levanta, pois, as questôes do ensino nas universidades e do processo decisório. As teorias não são isentas nem imparciais, apenas são adequadas como fundamentação teórica para estudos acadêmicos e como subsídios à tomada de decisóes quando tomadas com senso crítico ou até mesmo a reverso do conteúdo que veiculam. Elas podem conduzir intelectuais a caminhos incongruentes e lançar governantes contra interesses de seu povo.

\footnotetext{
* Professor de Relaçôes Internacionais da Universidade de Brasília - UnB. Emérito. Pesquisador Sênior do Conselho Nacional de Desenvolvimento Científico e Tecnológico - CNPq (alvervo@unb.br).

1 Publicamos uma informação sobre essa pesquisa em: CERVO, Amado Luiz. Formação de conceitos brasileiros de relaçóes internacionais. Carta Internacional, Universidade de São Paulo (Nupri), v. 3, n. 1, fev. 2008, p. 1-7.
} 
O trabalho focaliza três aspectos do tema. Em primeiro lugar, expõe-se o aspecto epistemológico: quais os substratos empíricos e os suportes mentais utilizados na elaboração de teorias e conceitos e como esses fatores condicionam seu alcance explicativo? Em segundo lugar, identificam-se quais são os criadores de conceitos e expõe-se o método que utilizam. Em terceiro, responde-se à questão da funcionalidade: para que servem os conceitos?

O campo de observação empírica e o suporte mental utilizados nesse texto com o fim de fundamentar a argumentação acerca do papel dos conceitos e ilustrá-la com exemplos envolvem as experiências brasileira e sul-americana. Delas extraímos fatos, pensamentos e contribuições. Pouco avançamos para além dessas fronteiras de observação, mas o caráter abstrato do texto insere-o na área dos estudos de relações internacionais em condições genéricas, com o fim de abrir um debate intelectual a respeito de conceitos e teorias.

\section{Teorias e conceitos: raízes e alcances diferenciados}

O estado atual das teorias das relações internacionais apresenta um quadro caótico do ângulo de sua formulação intelectual ${ }^{2}$. Esse fato, per se, aconselha o estudioso a tomá-las com cautela. Elas conservam, como afirma Marie-Claude Smouts, a função original de elaborar a compreensão do objeto de estudo, as relações internacionais, e de iluminá-lo com o conhecimento organizado ${ }^{3}$. Constituem, destarte, um corpus de conhecimento de grande utilidade, como se observa com teorias desenvolvidas por outras ciências humanas e sociais.

As teorias integram, no Brasil, os currículos dos cursos de relações internacionais, aproximadamente setenta cursos de graduação e cerca de uma dezena de cursos de pós-graduação de mestrado e doutorado. Isto é, exercem uma contribuição de ponta para a formação do pensamento e da inteligência nacional. Por outro lado, informam o processo decisório, como afirma em seminários o atual ministro brasileiro de relaçóes exteriores, Celso Amorim, por algum tempo professor de teoria das relações internacionais na Universidade de Brasília: quem não conhece a teoria não exercita a intuição conselheira da decisão ${ }^{4}$.

$\mathrm{O}$ caos a que nos referimos diz respeito a contradiçōes entre teorias e correntes teóricas que os manuais evidenciam. O caos também se observa em publicações, até mesmo de grandes mestres, que exibem interpretaçôes das relações internacionais sem se apresentarem como formuladores de teorias stricto sensu. Em nosso entender, o estado caótico das teorias explica-se pelo fato de não serem imparciais, já que se inspiram em campos de observação limitada, e pelo fato de não serem objetivas,

2 Ver, entre inúmeros compêndios, NOGUEIRA, João Pontes \& Messari, Nizar. Teoria das relaçôes internacionais: correntes e debates. Rio d e Janeiro: Elsevier, 2005.

3 SMOUTS, Marie-Claude (org.). Les nouvelles relations internationales: pratiques et théories. Paris: Sciences Po, 1998. 4 Ver textos de seminários publicados pela Fundação Alexandre de Gusmão (Funag). CERVO, Amado Luiz \& Bueno, Clodoaldo. História da politica exterior do Brasil. Brasília: EdUnB, 2008. 
já que outros campos de observação suscitariam o contraditório, enfim por não convencerem como explicação universal, como presumem.

A desconfiança intelectual invade com força ética o domínio das teorias das relações internacionais. As raízes em que se apóiam as vinculam a interesses específicos de determinadas sociedades que constituem seu campo de observação, bem como a valores que estas sociedades cultivam e, ainda, a padrões de conduta que sugerem e enaltecem como sendo ideais. Enquanto promovem tais fatores específicos, descartam interesses, valores e padróes de conduta de outras sociedades. O construtivismo, mélange das contradições da teoria, surge como reação de superação do impasse a que se chegou.

Desvendar as ciladas da teoria é tarefa tão relevante quanto apropriar-se de seu conhecimento. $\mathrm{O}$ realismo, por exemplo, trilhou o caminho do sucesso nas universidades e meios intelectuais de todo o mundo, de modo incomparável. A desqualificação dessa corrente teórica inicia com as evidências de sua origem nos Estados Unidos, no início da Guerra Fria, por tal razão estabelecendo o Estado como agente principal das relaçôes internacionais e a segurança como motivação primeira da ação externa. $\mathrm{O}$ realismo propõe ao mundo interesses, valores e padrões de conduta do Ocidente.

O realismo não é isento nem explica as relações internacionais como pretende. Às vezes pode convir a certas nações navegar contra o realismo, ensina Parola 5 . E acrescenta: a moral dele foi excluída desde a origem. Por que não se moveriam as relações internacionais contra o realismo, capaz de produzir a ordem injusta?

A crise das teorias elaboradas nos meios acadêmicos do centro do capitalismo e difundidas para o mundo tira explicação de suas carências de objetividade, isenção e alcance, por um lado, da irrupção dos países emergentes, detentores de metade da riqueza global, por outro. As teorias que servem ao Primeiro Mundo não são convenientes, necessariamente, aos emergentes. Tomemos, como exemplo, a teoria da estabilidade hegemônica.

Para Bertrand Badie, a teoria da estabilidade hegemônica, no mundo atual, exibe tanta capacidade explicativa para as relaçóes internacionais quanto uma eventual teoria da instabilidade hegemônica ${ }^{6}$. Esta última, com efeito, fundar-seia no suporte empírico de uma base de observação tão global quanto a primeira: o antiamericanismo ou a aversão natural à hegemonia; o terrorismo ou a reação de quem não tem meios de potência; a autonomia dos Estados ou a imitação da potência hegemônica pela conduta unilateral; a necessidade de entendimento multilateral para alcançar resultados em questôes vitais como clima, fome, formas de energia, comércio internacional, respeito aos direitos humanos, gerenciamento de conflitos locais, bilaterais ou regionais. Em suma, a ordem internacional não se ampara na potência hegemônica do momento se esta não for capaz de conectar-se

5 PAROLA, Alexandre Guido Lopes. A ordem injusta. Brasília, Funag, 2007.

6 BADIE, Bertrand. Limpuissance de la puissance: essai sur les nouvelles relations internationales. Paris: Fayard, 2004. 
com as forças globais de modo a agregar o peso destas últimas na criação da ordem. E nesse caso a teoria da estabilidade hegemônica esvazia-se.

Um contrapoder, com efeito, ergue-se daquele sul que os geopolíticos já denominaram periferia, depois terceiro mundo, hoje emergentes. Esse contrapoder, no entender de Dupas ${ }^{7}$, esparrama-se sobre todos os domínios das relações internacionais e desafia o poder institucionalizado no seio do capitalismo tradicional. Requisita novas formas de compreensão e explicação para as relações internacionais.

Examinemos apenas o efeito do contrapoder sobre o âmbito da negociação comercial. Desde a Segunda Guerra Mundial, a velha periferia assistia a decisōes elaboradas pelos países centrais do capitalismo no seio do Gatt-OMC e propostas como regras para todas as nações. A periferia não participava da formulação, tampouco usufruía de benefícios estruturais, por certo haveria de cumpri-las. Durante a Conferência de Cancun, em 2003, inserida na rodada Doha da OMC, os países emergentes não se alçaram contra a liberalização do comércio internacional, objetivo da rodada, porém contra o modo de produzir o acordo. Em Cancun, tudo ocorreria como no passado: um consenso entre os países ricos, proposto como ordenamento nos limites das possibilidades aceitáveis por eles mesmos. A continuidade do poder. Os emergentes organizaram-se então no G20 com o fim de participar, pela primeira vez, da formulação das regras de liberalização de modo a estabelecer a reciprocidade de benefícios. Caso não fosse possível atingir a reciprocidade, bloquear-se-ia a produção de regras multilaterais para o comércio internacional. A OMC paralisouse por anos em razão da emergência do contrapoder.

O contrapoder dos emergentes desequilibra o exercício do poder internacional da antiga Trilateral, Estados Unidos-Europa-Japão, da potência hegemônia, Estados Unidos, bem como da atual coalizão estratégica entre Europa e Estados Unidos. Faz do G8, ademais, um espetáculo de impotência, mesmo que os líderes do velho capitalismo escolham um G5 de emergentes representativos para assistir a suas reuniōes. O contrapoder enfraquece, enfim, todas as teorias atreladas à ordem internacional construída desde o centro e para o centro.

Não se trata apenas de observar o choque de interesses no domínio do comércio, da segurança, do meio ambiente e dos direitos humanos, como o dos migrantes, que a ordem do passado revela e as teorias animam.

Um exemplo de teorização das relações internacionais pertinente ao domínio dos valores, que correu o mundo e ainda fundamenta estudos, interpretaçóes e processos decisórios, nos é fornecido por Samuel Huntington ${ }^{8}$. Como toda teoria serve a uma cultura, o choque de civilizações serve à cultura ocidental de matriz anglo-americana. Brasil, Índia e China, entre outros países pacifistas, concebem e praticam políticas exteriores não confrontacionistas e pautam sua conduta pela

7 DUPAS, Gilberto. Atores e poderes na nova ordem global. São Paulo: Unesp, 2005.

8 HUNTINGTON, Samuel P. O choque das civilizaçôes. São Paulo: Objetiva, 2001. Ver MARTINS, Estevão Chaves de Rezende. Cultura e poder. São Paulo: Saraiva, 2007. 
convivência das diferenças culturais. Em particular, segundo Renato Ortiz, o Brasil é formado por cultura plural, oriunda de grupos sociais distintos, culturas que se transformam com o tempo?. E projeta espontaneamente sua identidade multicultural sobre a visão de mundo, como nos ensina Celso Lafer ${ }^{10}$. A teoria do choque de civilizações, ao sugerir o conflito ao invés da cooperação entre os povos, é avaliada pela inteligência desses emergentes como uma aberração intelectual.

Em seu livro The Central Liberal Truth: How Politics Can Change a Culture and Save it from Itself, Lawrence E. Harrison utiliza a lógica de Huntington ao perguntar-se sobre quais elementos de cultura promovem democracia, justiça social e desenvolvimento. Nesse e em outros estudos, examinou experiências de países em desenvolvimento, que elegeu como objeto de observação, e identificou mais de duas dezenas de fatores de propulsão e obstrução. Contudo, sua base de referência epistemológica prossegue sendo a cultura do Ocidente, que sobrepõe como filtro solar para captar as manifestaçôes da cultura em países do sul e verificar sua adequação ou não a uma teoria da superioridade da cultura ocidental ${ }^{11}$.

Quando se unem, Harrison e Huntington descartam o valor explicativo das interpretações que fizeram sucesso no sul, como as teorias do imperialismo, do colonialismo e da dependência, entre outras. Limpam, como se diz na gíria brasileira, a barra moral do capitalismo e embutem valores culturais do Ocidente na teoria que divulgam, como propagandistas ${ }^{12}$.

Revelando atitude intelectual mais aberta e mais simpática, Alexander Wendt escala uma nova fase dessa evolução recente das teorias. Construtivista, construtivista racionalista como se apresenta a si mesmo, surpreendeu o meio acadêmico em 1999 com seu livro Social Theory of International Politics. Wendt inicia a demolição do imperialismo das teorias das relações internacionais. Essas teorias, segundo o autor, nunca foram capazes de prever algo que já não fosse uma tendência em curso. Ávido por idéias novas, não hesita em colocar em cheque por meio de seu ecletismo metodológico o conhecimento disponível para explicar as relaçôes internacionais. $\mathrm{O}$ realismo, por exemplo. Existem três paradigmas de Estado, afirma: o hobbesiano, que vê os outros como inimigos, o lockeano, que os vê como rivais, e o kantiano, que os vê como amigos. Embora pretenda golpear o realismo, que opera em seu entender por meio do primeiro modelo, o argumento de Wendt permanece em certa medida tributário dessa corrente ${ }^{13}$.

Para os fins desse texto, recolhemos do acima exposto uma conclusão que nos permite passar à segunda parte de nosso argumento.

9 ORTIZ, Renato. Cultura brasileira e identidade nacional. São Paulo: Brasiliense, 1994. Ver CERVO, Amado Luiz. Multicultiralismo e política exterior: o caso do Brasil, Revista Brasileira de Politica Internacional, n. 38 (2), p. 133-146, 1995.

10 LAFER, Celso. A identidade internacional do Brasil: passado, presente e futuro. São Paulo: Perspectiva, 2001. 11 HARRISON, Lawrence E. The Central Liberal Truth: How Politics Can Change a Culture and Save it from Itself. Oxford: USA Trade, 2006.

12 HUNTINGTON, Samuel P. \& Harrison, Lawrence E. A cultura importa. São Paulo: Record, 2002.

13 WENDT, Alexander. Social Theory of International Politics. Cambridge: Cambridge University Press, 1999. 
No estado em que se encontram, as teorias das relações internacionais são limitadas em sua capacidade explicativa, normativa e decisória, visto que pesquisadores recentes avançam na identificação de interesses, valores e padrões de conduta de múltipla procedência que inserem em sua interpretação de modo implícito ou explícito. Entre as nações, a diversidade desses três fatores prepondera. Tal constatação objetiva torna como que impossível qualquer teoria de alcance universal. Muito ilustrativa dessa crise do conhecimento é a reação da terceira geração de teóricos da escola inglesa (Alexander Wendt, Andrew Linklater, Tim Dune e Nicholas Omuf), os quais desvendam as armadilhas escondidas por trás do tradicional conceito de sociedade internacional e de seu papel na produção de regras componentes da ordem internacional ${ }^{14}$.

Do ângulo epistemológico, o construtivismo encaminhou a avaliação crítica das teorias, sem conduzir sua lógica ao termo do raciocínio. Deixou em aberto a confusão mental, por não haver estabelecido nexo de inspiração entre fatores nacionais ou regionais e elaboração teórica. A ousadia consiste em descartar de vez a pretensão universalista das teorias e limitar-se a erguer conceitos aplicados às relações internacionais. Estes não renegam suas raízes nacionais ou regionais interesses, valores e padrões de conduta - por tal razão não se apresentam com a ambição explicativa universal das teorias.

\section{Os construtores de conceitos}

Nas duas partes seguintes desse texto, a experiência brasileira fornece a base de observação para coleta dos dados do estudo. A sistematização dos conceitos brasileiros aplicados à inserção internacional do país é vista, desde agora, como contribuição do intelectual ao estudo das relações internacionais. O conjunto de conceitos articulados entre si e com o campo do conhecimento das relações internacionais foi exposto em nosso livro Inserção Internacional ${ }^{15}$. $\mathrm{O}$ conjunto aproxima-se da teoria, na medida em que exerce as duas funçôes que a disciplina se atribui historicamente, a explicativa e a valorativa. Diferencia-se da teoria, na medida em que restringe o alcance às relações internacionais de um determinado país.

A crítica à construção de teorias exposta na primeira parte desse texto reivindica, em nosso entender, a multiplicação de formulaçôes com o fim de abarcar conjuntos explicativos e conjuntos valorativos diversos, de tal sorte que não permaneçam alguns povos ou nações à mercê de outros no terreno da formação acadêmica e das decisões políticas. Foi com esse intento que nos ocupamos durante três anos com o projeto de pesquisa apoiado pelo CNPq, de que resultou nosso livro.

14 SOUZA, Emerson Maione. A escola inglesa no pós-guerra fria: fechamento, tradicionalismo ou inovação? Cena Internacional, v. 8 (2), 2006, p. 29-62.

15 CERVO, Amado Luiz. Inserção internacional: formação dos conceitos brasileiros. São Paulo: Saraiva, 2008. 
Agregamos ao estudo das relações internacionais a contribuição brasileira, substantiva pelo lado cognitivo e legítima pelo lado ético. Sem estarmos preocupados em elaborar mais uma teoria e sem recusarmos a idéia de que um conjunto de conceitos possa ser comparado a uma teoria pelo fato de exercer idênticas funções.

Centramos, a seguir, o foco em duas questôes relativas à formação dos conceitos brasileiros de inserção internacional: em primeiro lugar, são indicados os criadores de conceitos e a abrangência de suas formulações; em segundo, para fins pedagógicos, são examinadas e demonstradas as funções específicas desses conceitos aplicados às relaçôes internacionais.

O estudo de conceitos elaborados no interior de uma nação, ou numa determinada região de similaridade cultural e de desígnios externos, é conduzido em nossa pesquisa por método predeterminado, não eclético, como procedem construtivistas, a exemplo de Wendt. Os procedimentos de nosso método são sumariamente expostos a seguir.

Por mais pretensioso que se apresente, o intelectual que lida com as relaçōes internacionais não arranca de sua mente o conceito acabado. A contribuição pessoal é relevante, na medida em que a destilação de conceitos, o arranjo, a tipificação e a conexão evolutiva, uma soma de tarefas da qual resulta a síntese superior, pertence ao autor, que por vezes acrescenta de próprio. Algo semelhando ocorre no campo das teorias, como bem sabem os estudantes de relações internacionais: num extremo, manuais que expõem as teorias alheias; em outro, criações originais e pessoais; no meio situa-se nosso procedimento, uma sistematização de conceitos extraídos, seja de determinada praxis, em viagem do empírico ao abstrato, seja de determinada inteligência elaborada coletivamente.

Com efeito, o conceito aplicado às relaçôes internacionais com o qual estamos lidando resulta de uma construção social. Os conceitos brasileiros, objeto desse estudo, lançam raízes em três segmentos da sociedade: os pensadores da nação, de seu destino e de seu lugar no mundo; os pensadores da vida política e da ação diplomática; enfim, o meio acadêmico e os centros de produção científica que analisam metodicamente a conexão entre o interno e o externo. Nosso método de análise aproxima-se dos procedimentos de outras correntes e grupos, mas sequer deve ser qualificado de construtivista. O método tradicional de elaboração das teorias está mais para a dedução, daí sua fragilidade intrínseca, o construtivista explora uma base de observação dispersiva e exibe certo ecletismo, ao passo que nossos procedimentos para produção dos conceitos apóiam-se na segurança do método histórico, em sua essência, percorrendo o caminho da indução que vai do concreto ao abstrato.

\section{Pensadores de expressão nacional}

Em que mundo vivemos? Tem o Brasil um lugar especial no mundo? Que mundo se deseja para a humanidade? Qual o papel a desempenhar sobre o cenário 
internacional. Sem serem políticos, diplomatas ou cientistas, alguns brasileiros se inclinaram sobre tais questões e formularam pensamento a tal respeito, de modo a impregnar o substrato cultural da mente coletiva. Esses pensadores devem ser procurados na literatura propriamente dita, nos personagens que ela cria e que refletem o meio diverso em que vivem e as visões que nutrem de si, dos outros, de brasileiros e de estrangeiros, da nação e do mundo. São encontrados também na plêiade de pensadores que não figuram em manuais de história da literatura, porém deixaram suas idéias em obras que compõem o acervo cultural da nação. Pela força da leitura, da citação, da aprendizagem ou mesmo do subconsciente, a mensagem desse segmento do pensamento nacional revive e se perpetua.

Observamos no procedimento inglês e de intelectuais de outros países europeus o modo como a inspiração do estudo das relaçôes internacionais retira do acervo de pensadores clássicos idéias e interpretaçôes de inestimável valor. Brunello Vigezzi descreve em valiosos estudos a conexão entre a escola inglesa e os mestres do passado ${ }^{16}$. Conexão similar convém estabelecer, por exemplo, entre fundadores da antropologia brasileira que escreviam na virada do século XIX para o XX, pensadores da semana de arte moderna de 1922 e do grupo do Instituto Superior de Estudos Brasileiros (ISEB) dos anos 1950 com a interpretação das relações internacionais do Brasil.

Para Manuel Bonfim, os males da civilização dos trópicos não advêm da raça ou do clima, porém do modelo de inserção internacional. Por que não libertar a América Latina do jugo externo e estimular seu dinamismo, tomando como fatores de propulsão energias próprias? O otimismo de Bonfim inspira os intelectuais dos anos 1920, como Oswald de Andrade, o modernista, e, na década seguinte, Gilberto Freire, o sociólogo, quando o Brasil dava seu salto de modernização. Democracia racial associada à ideologia do trabalho, eis a solução para o dilema não resolvido da mestiçagem, ensina Freire. $\mathrm{O}$ nacionalismo de isebianos e dos fundadores da Revista Brasileira de Politica Internacional (1958) nada tinha de hobbesiano. Hélio Jaguaribe, Cleantho de Paiva Leite, Afonso Arinos e outros pensadores tomavam consciência do atraso econômico e requeriam a autonomia da política exterior como instrumento necessário de promoção da prosperidade.

Os pensadores que forjam a cultura da nação lançam as sementes de paradigmas de Estado, tão caros à teoria das relaçôes internacionais. Morgenthau expressa a súmula do pensamento social norte-americano do início da Guerra Fria, ao elaborar sua teoria "realista" do Estado hobbesiano. Wendt expressa a súmula do pensamento clássico europeu, ao elaborar sua teoria "construtivista" dos três Estados, hobbesiano, lockeano e kantiano. Mas no Brasil, nenhuma dessas formulações teóricas tem assento na cultura nacional. Com efeito, esta inspira

16 VIGEZZI, Brunello. The British Committee on the Theory of International Politics (1954-1985): the Rediscovery of History. Milano: Unicopli, 2005. Ver sua longa introdução em BULL, Hedley \& Watson, Adam. L'espansione della società Internazionale. Milano: Jaca Book, 1993. 
quatro conceitos de Estado, longamente expostos em Inserção Internacional: liberal-conservador, desenvolvimentista, neoliberal e logístico.

O paradigma liberal-conservador estende-se da Independência a 1930, baseado na apropriação do liberalismo clássico europeu e responsável por manter o atraso histórico da nação segundo análise estruturalista dos pensadores da Comissão Econômica para a América Latina (Cepal). O desenvolvimentista é destilado do pensamento modernizador de que demos algumas referências e induziu as conquistas do progresso durante sessenta anos. O neoliberal dos anos 1990 representa uma volta ao passado pela subserviência que pratica e, ao mesmo tempo, um salto para o futuro, quando abre economia e sociedade aos fluxos da globalização. O logístico, enfim, no século XXI, que transfere à sociedade e a seus agentes as responsabilidades do desenvolvimento, sem deixá-los a mercê do mercado porque lhes dá suporte em sua ação externa.

A cultura brasileira é componente congênito desses e dos demais conceitos aplicados às relações internacionais do país.

\section{O pensamento político e diplomático}

Em todo país do mundo, homens de Estado desenvolvem idéias acerca do modo de conceber o sistema internacional, sua estrutura e funcionamento, a economia internacional, bem como as relações do país com estruturas e conjunturas e com as outras naçôes. Estamos nos referindo a dirigentes, em especial os diplomatas, que desempenham funções relevantes para a formação nacional.

As correntes brasileiras do pensamento político e do pensamento diplomático carregam como legado histórico a identidade pluralista em que nasceu, cresceu e amadureceu a nação, cujo curso profundo repousa sobre substrato étnico-cultural múltiplo. $\mathrm{Na}$ esfera das idéias políticas e diplomáticas aplicadas às relações internacionais do país, esse substrato oferece base real, porém os pensadores se alçam com desenvoltura. Examinemos, por exemplo, duas tendências relevantes: o pensamento liberal e o pensamento industrialista.

Um país liberal, aberto aos fluxos de idéias, conhecimentos, pessoas, capitais, produtos; conectado com o mundo não só por meio desses fluxos, mas por ordenamentos que os convertem em organização institucional, regras de direito, garantia de estabilidade e previsibilidade, regras, portanto, inspiradoras da conduta da sociedade e do Estado sobre o cenário internacional: essa linha de pensamento não emerge no Brasil à era de Fernando Henrique Cardoso e dos neoliberais do fim do século XX. A abertura ao mundo penetra a cultura e a vida política brasileira como fator imanente de sua história. Assim pensava D. João VI quando concebia, em 1808, a liberdade para o comércio e as manufaturas no Brasil: construir o império americano ancorado no aumento da riqueza, cuja possibilidade seu conselheiro, José da Silva Lisboa, o primeiro economista liberal brasileiro, condicionava à contribuição interna e ao livre comércio. Nessa visão de 
conveniente abertura ao mundo, José Bonifácio de Andrada e Silva, o pai da pátria, concebia à época da Independência a nação a construir. Jamais desconectou-se a vida política dessa corrente liberal ao longo de toda a história nacional.

Um país industrial não foi pela primeira vez conceituado por Getúlio Vargas ou Juscelino Kubitschek, dois estadistas modernizadores do século XX. A linha de pensamento teve precursores distantes. A gênese do pensamento industrialista brasileiro vem embutida em medidas como Carta Régia, decreto e alvará tomadas em 1808 e 1809 por D. João, sob inspiração de seu conselheiro. A corrente se reforça, ao adquirir consistência racionalizada nos textos de Nicolau Pereira de Campos Vergueiro e Raimundo José da Cunha Matos nos anos 1820, Bernardo Pereira de Vasconcelos e Sales Torres Homem, entre outros, no decorrer do no século XIX. O liberalismo radical da segunda metade do século XIX, tão bem expresso por Tavares Bastos, colocava-se a serviço da sociedade primário-exportadora, uma organização voltada à manutenção do atraso histórico por elites sociais que se haviam apropriado do Estado e dele se serviam com exclusividade. Da mesma forma, no século XX e XXI, porém sob novas e adaptadas formulações, como democracia de mercado, globalização benéfica, governança global, liberais radicais se colocam a serviço de interesses da elite das nações, que estabelece em proveito próprio o ordenamento global. Os pensadores que conceberam através do tempo o paradigma liberal-conservador de relações internacionais dominaram o exercício do poder dos dirigentes por mais de um século, desde a Independência até a revolução de 1930, precisamente. A tendência liberal imprimiu traços indeléveis na formação nacional. Já os pensadores que inspiraram o paradigma desenvolvimentista pela via da modernização industrial, depois de observarem sua voz ressoar no deserto durante tão longo tempo, a profetizar o futuro, acabariam substituindo os primeiros de $1930 \mathrm{em}$ diante.

Os conceitos brasileiros aplicados à inserção internacional do país são múltiplos e por vezes complementares, como estas duas correntes acima referidas, capazes de produzir o equilíbrio do modelo de inserção ou modelos contraditórios. No fundo, a sociedade brasileira sempre foi liberal, até mesmo porque esse lastro ideológico serviu de ambiente e fermento para a germinação de conceitos contraditórios.

Liberal era a sociedade, e aberta ao mundo, pensava D. Pedro II, ao visitar os Estados Unidos, a Europa, a Rússia, o Próximo Oriente e o Egito, durante a segunda metade do século XIX. Ao despachar para a China, em 1879, uma grandiosa missão com o fim de estabelecer com o Celeste Império o comércio, as relações diplomáticas e o fluxo migratório. Para industrial evoluía a sociedade, por tal razão Ernesto Geisel concebia um país no topo da escala do desenvolvimento, com tecnologias de ponta, empreendimentos de vulto e parcerias estratégicas diversificadas, no momento em que os Estados Unidos perdiam peso sobre a cena internacional e criavam dificuldades à conquista do último estágio do desenvolvimento. Exigências do segundo paradigma histórico sugeriam outras conexões externas, com Alemanha, 
Itália e Japão, por exemplo, os quais se dispunham a oferecer fatores de prosperidade sonegados pela potência hegemônica da área.

Nessa práxis e nesse substrato étnico-cultural pluralista inspiraram-se Oswaldo Aranha, Araújo Castro, Afonso Arinos, San Tiago Dantas e Ramiro Saraiva Guerreiro para conceituar o universalismo da diplomacia brasileira, ao qual alguns dirigentes seus contemporâneos, a exemplo de João Neves da Fontoura e Vasco Leitão da Cunha, impunham limites por meio do conceito de ocidentalismo, uma estratégia de ação externa excludente.

De modo similar, globalistas epistêmicos, como o grupo assessor de Carlos Saúl Menem na Argentina (entre os quais Carlos Escudé, Andrés Cisneros e Felipe de la Balze) e o grupo assessor de Fernando Henrique Cardoso no Brasil (entre os quais Pedro Malan e Celso Lafer), extraíram do liberalismo genético de suas naçôes, bem como de consensos e conselhos externos, inspiração para elaborar e programar a vigência do paradigma neoliberal de inserção internacional, uma criação da inteligência política latino-americana dos anos 1990, que não foi concebida de modo uniforme por todos os dirigentes regionais, porém apresentava componentes comuns. O pensamento neoliberal não foi adotado no Brasil sem reação social, visto que outra tendência imanente à história impregnava a cultura política. Aliás, deu origem, dentro do próprio grupo dirigente neoliberal, ao pensamento cético quanto a possíveis efeitos econômicos e sociais e teve de ser temperado com outros conceitos, como o de globalização assimétrica e de Estado logístico, que fariam sucesso logo mais, quando os dirigentes neoliberais foram substituídos no início do século XXI.

\section{O meio acadêmico e os centros de pesquisa}

Além de grandes intelectuais, pensadores da nação, e dirigentes, como homens de Estado, políticos e diplomatas, o meio acadêmico e os centros de pesquisa contribuem para a formação de conceitos aplicados às relações internacionais do país. Por vezes as mesmas pessoas integram dois e até mesmo os três grupos acima referidos. Para efeito didático, contudo, convém separar os formadores de opinião que se localizam nos centros de pesquisa e ensino. Isso porque influem sobre a mídia, os movimentos de opinião, os resultados eleitorais e as políticas públicas. Sobretudo influem sobre a formação mental e profissional dos dirigentes. Uma influência, aliás, profunda e duradoura, aquela que se exerce sobre o modo de pensar e agir. A esse terceiro segmento social construtor de conceitos cabe a responsabilidade de avaliar a todos os conceitos, tendo por referência sua capacidade de propulsão ou obstrução do desenvolvimento e do bem-estar da nação, quando postos em prática. Cabe, em especial, desvendar as ciladas das teorias que servem ao desenvolvimento e ao bem-estar alheio e prejudicam o nacional.

Em cada linha de pensamento que dá origem a determinados conceitos aplicados à inserção internacional, localizam-se estudiosos com suas aulas, 
conferências e publicações. Uma obra que expõe os conceitos brasileiros de relaçōes internacionais, como fazemos com nossa Inserção Internacional, convém que apresente no caput de cada capítulo um elenco de autores, cujas leituras são recomendadas para que o leitor possa aprofundar aquela linha de pensamento e os conceitos que escondem seu itinerário.

Tomemos o exemplo das relações com a vizinhança. $\mathrm{O}$ peso das relações entre Brasil e Argentina influiu durante dois séculos sobre a formação de conceitos destinados a explicar e comandar decisões acerca das relações do Brasil com seus vizinhos da América do Sul.

Quem não lembra, ao revolver o século XIX, os longos debates acerca da intervenção, da não-intervenção, da neutralidade, como se dizia então, da legitimidade e ilegitimidade da guerra de conquista, das fronteiras naturais, da herança portuguesa ou espanhola? Do seio desse fermento intelectual e da práxis brota um conceito como prevalência de determinada corrente de pensamento, conceito esse denominado pela historiografia de cordialidade oficial da diplomacia brasileira. A defesa desse padrão de conduta, revelam estudos recentes, vem exposta em argumentos históricos de longa data, desde a época do Visconde do Rio Branco e de seu filho, o Barão. Assenta sobre dados de raciocínio que estudiosos tornaram explícitos: a grandeza do país, a convivência necessária, a prosperidade que a todos interessa, a boa imagem a cultivar em razão dos efeitos que exerce sobre a opinião e os dirigentes, a paz a manter, a tranqüilidade das fronteiras. Esses e outros fatores encontram-se na origem do conceito da cordialidade oficial. Ela induz uma conduta em que sobressai a ação cooperativa em vez do confronto, a humildade em vez da empáfia política, a negociação em vez da ostentação de força, o silêncio por vezes no lugar do rompante próprio dos caudilhos. A cordialidade oficial não prejudica, ao contrário favorece a qualidade das relações com a vizinhança e promove os interesses de todos. Pode ser sacrificada em situação de impasse, não a qualquer pretexto - visto que a degradação do ambiente regional produz os piores efeitos -, se porventura o superior interesse nacional o requer.

Nesse exemplo, observamos a gênese de um conceito e seu caminho para a maturidade, por meio do cruzamento de influências de três origens: pensadores da nação, diplomatas e pesquisadores.

Contudo, o conceito de cordialidade oficial não basta para compreender e orientar a política brasileira para a vizinhança. $\mathrm{O}$ acervo de conceitos disponíveis a respeito desse ramo da ação externa revela a existência de outros conceitos, também forjados ao longo do tempo, que se aplicam à visão do outro e ao comando da política regional brasileira: rivalidade, cooperação e conflito, relações cíclicas e relações em eixo. Eles dão inteligibilidade ao real, porque abrigam cada qual parcela da verdade, e induzem a conduta do governo e dos agentes sociais, sugerindo previamente a melhor decisão no sentido de controlar as relações com a vizinhança pela distribuição de efeitos em benefício de uns, de outros, ou de 
todos. Desse modo, exercem, em conjunto, as duas funções de uma teoria das relações do Brasil com a vizinhança: a explicativa e a valorativa.

Pesquisadores brasileiros e de países vizinhos estenderam-se, em seus trabalhos, sobre os componentes de cada um desses conceitos. Quanto à rivalidade, os fatores de determinação que agem ao longo do tempo e as manifestações concretas. Quanto ao paradigma da cooperação e conflito, um estereótipo da literatura, o modo como a primeira agrega ao segundo elementos de equilíbrio e outras manifestações se sucedem. Quanto às relações cíclicas, a descoberta de estudiosos de que nem cooperação nem conflito imprimem curso contínuo, que oscila, pois, em razão de variáveis intervenientes capazes de produzir a reversão de uma tendência. Quanto às relações em eixo, o nível mais avançado das análises disponíveis sobre as relações com a vizinhança, os estudiosos colocam em evidência em sua origem a dimensão do que seja a relação especial, a união co-responsável com o parceiro, a esfera de elaboração política comum e o cálculo da reação de terceiros na região. Relações em eixo entre duas potências maiores em determinada região explicam a gênese dos processos de integração, como entre França e Alemanha na Europa e entre Brasil e Argentina na América do Sul.

Além de nossas publicações a respeito dos conceitos que informam as relações do Brasil com a vizinhança, leiam-se os estudos de argentinos, entre os quais Mario Rapoport, Eduardo Madrid, Raúl Bernal-Meza, Aldo Ferrer e Miguel Angel Scenna; e de brasileiros como, Moniz Bandeira, Francisco Doratioto, Raquel Miranda, Heloisa Vilhena de Araújo e Celso Lafer.

Conceitos destinam-se a integrar conhecimento, servindo como amálgama da reflexão que organiza a matéria empírica, base de observação científica da vida política e da realidade econômica, social e histórica. Caso não sejam produzidos sob tais critérios, dificilmente vão além do divertimento intelectual fruto do imaginário ou da fé e, nessas condições, não exercem as funções explicativa e valorativa de que estamos tratando ao discorrer sobre conceitos que fundamentam o modelo brasileiro de inserção internacional.

Conceitos presidem os diversos campos de estudo das relaçōes internacionais em geral e das relações internacionais do país. Orientam, ademais, as diversas áreas da ação externa, seja do Estado, como agente de primeira linha, seja de outros agentes sociais, internos, externos ou conjuntos. Em nosso estudo sobre a formação desses conceitos, o objetivo foi de expressar sua riqueza e diversidade, um rol eloqüente pela quantidade, cujos exemplos acima expostos a título de amostragem permitem ao leitor avaliar o conjunto.

Por que não mencionar outros, ao menos de passagem, em razão do grande alcance epistemológico e da grande operacionalidade que ostentam? Pensamos no conceito de transição na História do país, seja de paradigma seja de regime político, e seu impacto sobre a política exterior e o modelo de desenvolvimento; pensamos no acumulado histórico da diplomacia brasileira, um conjunto de valores, princípios e padrôes de conduta que lhe dão previsibilidade e credibilidade; 
na parceria estratégica, seja com substrato real seja como mera retórica política; no desenvolvimento associado contraposto ao desenvolvimento autônomo, o racha entre correntes de direita e de esquerda, nacionalistas e independentistas; pensamos no multilateralismo kantiano e no multilateralismo da reciprocidade, o racha entre utópicos e realistas quanto à visão de mundo; nas relaçôes inter-societárias, conceito que aplicamos às esferas do turismo, das migrações e da cooperação acadêmica e técnica; na vocação industrial a preservar, aplicável às relações com as grandes potências e às negociações multilaterais e bilaterais; na internacionalização econômica, conceito imanente ao paradigma logístico de inserção internacional à era da globalização; nas relaçôes triangulares, que evidenciam interveniência de terceiros em esquemas bilaterais ou interblocos; pensamos, enfim, em hegemonia e estruturas hegemônicas, aplicáveis à produção do ordenamento global em que se movem países em desenvolvimento ou emergentes ${ }^{17}$.

\section{Para que servem os conceitos?}

Duas são, em nosso entender, as utilidades de um conjunto de conceitos de matriz nacional ou regional: reavaliar o papel das teorias de relaçóes internacionais e desvendar suas ciladas, por um lado; por outro, estabelecer a capacidade explicativa e valorativa de que são dotados e expor sua operacionalidade.

\section{Banir o imperialismo epistemológico das teorias de relações internacionais}

É chegado o momento de repensar a função da disciplina de teoria das relaçóes internacionais que ocupa lugar de destaque nos currículos dos cursos de graduação e pós-graduação. Nunca é suficiente insistir sobre as armadilhas da teoria: embutir interesses e valores de meios intelectuais em que são elaboradas, com fins conscientes ou inconscientes de promover a desigualdade entre as nações, em âmbito global. Tanto teorias quanto conceitos evidenciam o fato de que as naçôes cultivam valores próprios e desejam vê-los disseminados, precisamente porque os prezam; tanto teorias quanto conceitos orientam as nações em sua ação externa com o fim de realizar interesses de seus povos. A legitimidade de teorias e conceitos, vistos do ângulo dos valores e interesses que veiculam, é inegável.

Inegável também é o caráter nocivo à formação nacional ou regional, à definição da ordem internacional e às relações entre os povos assimilar pensamento, cultura, valores e interesses alheios como sendo próprios. Por isso, as teorias exercem forte propulsão à ordem injusta, depois de se posicionarem em sua gênese. Por isso servem a uns em detrimento de outros, sendo responsáveis pelo sistema internacional de prevalências unilaterais de benefícios. Estimulam, ademais, a tendência de padronização do mundo em detrimento da diversidade

17 Remetemos o leitor para às leituras recomendadas no início de cada capitulo de Inserção internacional, op. cit. 
que tanto encanta a convivência dos povos. Tudo isso em razão do caráter universalista com que se vestem.

Conceitos - e não as teorias - descobrem no coração dos povos o que lhes convém em termos de cultura e interesses. Se ocuparem o lugar das teorias, propõem ação externa de respeito ao alheio e de equalização de benefícios da ordem internacional. Orientam os dirigentes para o caminho da reciprocidade. No âmbito das relações internacionais, exibem a legitimidade que as teorias ignoram. Como desempenham tais funções? Propomo-nos responder a seguir.

\section{As funções dos conceitos derivadas de sua natureza cognitiva}

O estudo acerca da formação dos conceitos aplicáveis ao modelo brasileiro de inserção internacional identifica quatro características que são observadas em sua gênese, significado e alcance operacional: a) uma construção social; b) expressão da historicidade; c) inclusão de mensagem positiva; d) enfim, produção como exigência da ordem metodológica em respeito à verdade e ao rigor. Esses traços, de caráter metodológico e epistemológico, garantem a qualidade de conceitos que se propõem exercer as funções explicativa, valorativa e operacional das teorias.

$\mathrm{Na}$ literatura especializada encontram-se reflexões acerca da construção de conceitos, de sua natureza e de seu papel. Entre outros intelectuais que se inclinaram sobre tais preocupaçōes, os estudos de Carlo Ginzburg, Thomas Kuhn e Walter Benjamin nos auxiliam em razão da metodologia que aplicam para orientar a tarefa do pesquisador. Os quatro pressupostos acima referidos levam em conta procedimentos destes e de outros autores, especialmente a relação entre conceito e cultura, porém nossa pesquisa vai além, ao transladar conceitos para o campo das relações internacionais e examinar sua relação também com o interesse nacional e com o modelo de inserção internacional. Em outros termos, acrescentamos de próprio nesse intento de fazer da construção de conceitos um exercício útil, tanto sob o aspecto cognitivo quanto prático, e direcionado, especificamente, para o campo de estudo das relações internacionais.

Em primeiro lugar, o conceito como construção social e expressão, a esse título, de determinada cultura e de determinado ambiente acadêmico. Como vimos, nossos conceitos são extraídos de grandes pensadores brasileiros, cujo pensamento se volatiliza para aflorar, seja na esfera da formulação política e diplomática, seja na esfera da pesquisa de intelectuais e acadêmicos. Aflora, desabrocha, amadurece e frutifica como expressão social, estoque cultural, acervo mental. $\mathrm{O}$ caráter nacional incrustado na formação de conceitos brasileiros incorpora por certo a influência estrangeira. Não se trata, portanto, de animar nacionalismos ou chauvinismos de qualquer intensidade. Entre ilhas, territórios e continentes mentais não existem fronteiras geopolíticas, esse pressuposto conduz o procedimento que adotamos e sugerimos para o estudo de outras experiências. 
Em segundo lugar, os conceitos expressam historicidade. Penetram a estrutura profunda das coisas concretas, como ensina Benjamim. Por serem abstrações, exercem mediação entre sujeito cognoscente e objeto que apreendem. Exibem, portanto, entidade ontológica autônoma que se posta entre ambos. Depois de construídos, os conceitos têm existência própria e se agregam ao corpus de conhecimento voltado para as relações internacionais. Nascem e morrem, como os fenômenos históricos. Convém observar que o alcance de determinado conceito não esgota, necessariamente, o significado do fenômeno a que se refere, para alegria de outros artífices, que mais cedo ou mais tarde desmontarão velhos e construirão novos conceitos. Por outro lado, os conceitos são consistentes quando exibem a continuidade e a ordem por sobre a volatilidade e a complexidade, sem se apresentarem como dogmas de fé com que se presuma conhecer e ou se possa domar o real.

Em terceiro lugar, os conceitos embutem mensagem positiva. Em todos os tempos e em todas as culturas, como também em todas as disciplinas acadêmicas, identificamos pensadores da desgraça e catadores de lixo da humanidade. Sejalhes preservado o direito de investigar, mesmo porque a desgraça persegue a vida e o lixo pertence à realidade concreta. Os conceitos de que tratamos, contudo, embutem mensagem positiva, porque se destinam a expressar valores, aqueles que compõem determinado lastro cultural, e inspirar decisões, aquelas que elevam o bem-estar do povo. Se não incluir mensagem positiva dessa natureza, o conceito para nada serve, quando não prejudica. Por que devotar-se, então, à tarefa de erguê-lo?

Em quarto lugar, o conceito desvenda o novo e constitui, destarte, um ponto de ruptura com relação a fenômenos preexistentes ou coexistentes entre os quais se estabelece. Resulta, portanto, da exigência da ordem metodológica, como explanação de outro arranjo entre componentes ou variáveis que entrelaçam o fenômeno. $\mathrm{O}$ conceito espelha nova verdade. Mesmo quando relativo a idêntica historicidade, esse caráter de nova verdade desliza do novo arranjo por meio do rigor de observação, análise e reflexão. Se o construtor do conceito dotá-lo de tais atributos, deve exibi-lo, não permitir que se acanhe, ao contrário, ostentá-lo como nova afirmação hegemônica. $\mathrm{O}$ conceito é produto de pensamento alimentado, no caso das relaçôes internacionais, pela base cultural da nação, pela leitura que dirigentes fazem do interesse nacional e pela avaliação crítica das pesquisas, tudo isto concebido como o sistema de referência que o inspira.

\section{Conclusão}

Erguer conceitos aplicados à inserção internacional do Brasil equivale a metódico exercício mental feito com os fins de produzir conhecimento e levar compreensão à vida internacional, além de espelhar a práxis e sugerir caminhos de ação. Quatro procedimentos metodológicos orientam nossa produção de conceitos: construção social, historicidade, mensagem positiva e exigência da 
ordem metodológica. Tais procedimentos diferenciam nosso estudo daqueles conduzidos por Alexander Wendt sobre o papel das idéias nas relações internacionais: idéias como objeto acabado em contraposição a idéias como matéria-prima da pesquisa. E nos aproximam dos estudos de Celso Lafer em âmbito nacional e de Raúl Bernal-Meza em âmbito regional latino-americano ${ }^{18}$. Além de Parola, também um construtor de conceitos, a quem já nos referimos, Carlos Escudé adapta em dois livros a teoria realista à interpretação das relaçooes internacionais da Argentina para convencer o leitor da improbidade do translado dessa teoria de uma experiência para outra ${ }^{19}$.

A metodologia que utilizamos ganharia com a multiplicação de estudos referentes a outras experiências nacionais ou regionais. Elaborar um conjunto de conceitos e colocá-lo ao lado de outros e mais outros decorrentes da multiplicidade de experiências nacionais ou regionais inventa novo modo de estudar a vida internacional, capaz de libertá-la dos males que o conjunto atual das teorias impõe às mentes através do ensino e aos quais sugere às sociedades e aos governos que se submetam por meio da ação externa.

Contribuir para o fim das teorias de relações internacionais e para sua substituição por conceitos aplicados às relações internacionais propõe-se como caminho para transição do sistema internacional posto a serviço de interesses, valores e padróes de conduta das velhas estruturas do capitalismo para outro que acolha interesses, valores e padrões de conduta dos países emergentes. Propõe-se evolução mental correspondente à evolução material em curso.

Recebido em 15 de abril de 2008 Aprovado em 15 de agosto de 2008

\section{Resumo}

As teorias de relações internacionais não são isentas nem imparciais, visto que estão vinculadas a interesses, valores e padrões de conduta das sociedades onde são elaboradas e descartam esses fatores de outras sociedades. As teorias que servem ao primeiro mundo não são necessariamente convenientes para os países emergentes. O artigo propõe substituir teorias por conceitos aplicados ao estudo das relações internacionais. Os conceitos expõem o lastro nacional ou regional sobre os quais se assentam. A experiência brasileira corresponde ao campo de observação desta pesquisa. O conjunto de conceitos elaborados sugere outros estudos de caso. A nova abordagem das relações internacionais visa prover explicação, orientar projetos de pesquisa e formar a inteligência dirigente.

18 BERNAL-MEZA, Raúl. América Latina em el mundo: el pensamiento latinoamericano y la teoría de relaciones internacionales. Buenos Aires: Nuevohacer, 2005.

19 ESCUDÉ, Carlos. Realismo periférico: fundamentos para la nueva política exterior argentina. Buenos Aires: Planeta, 1992. Idem. El realismo de los Estados débiles: la política exterior del primer Gobierno Menem frente a la teoría de las relaciones internacionales. Buenos Aires: Grupo Editor Latinoamericano, 1995. 


\begin{abstract}
Theories of International Relations are neither free from bias nor impartial. They are linked to specific interests, values, and patterns of conduct in certain societies which constitute their field of observation. They discard these factors of other societies. So, the theories which serve the First World are not convenient, necessarily, to emerging countries. This text proposes to substitute theories by concepts applied to the field of the study of international relations. Concepts expose the national or regional roots on which they stand. The Brazilian experience furnishes the observation base for the study's data gathering. This collection of concepts has two functions historically attributed to theory courses: providing explanations and values.
\end{abstract}

Palavras-chave: Teoria das relações internacionais. Conceitos em relações internacionais. Conceitos internacionais brasileiros.

Key words: International Theory. International Concepts. Brazilian concepts on International Relations. 